\title{
Erratum to: Epidemiology and outcome of the cardio-renal syndrome
}

\author{
Dinna N. Cruz • Mihai Gheorghiade • \\ Alberto Palazzuoli • Claudio Ronco • \\ Sean M. Bagshaw
}

Published online: 10 May 2011

(C) Springer Science+Business Media, LLC 2011

\section{Erratum to: Heart Fail Rev}

\section{DOI 10.1007/s10741-010-9223-1}

Unfortunately there were typos in the name and address of third author in the original version. The correct name and affiliations of the third author are listed below:
Name: Alberto Palazzuoli.

Affiliation: Department of Internal Medicine and Metabolic Disease, Cardiology Section, University of Siena, Siena, Italy.

The online version of the original article can be found under doi:10.1007/s10741-010-9223-1.

D. N. Cruz · C. Ronco

Department of Nephrology, Dialysis and Transplantation,

San Bortolo Hospital, Vicenza, Italy

M. Gheorghiade

Division of Cardiology, Northwestern University Feinberg

School of Medicine, Chicago, IL, USA

A. Palazzuoli

Department of Internal Medicine and Metabolic Disease,

Cardiology Section, University of Siena, Siena, Italy

S. M. Bagshaw ( $\varangle)$

Division of Critical Care Medicine, University of Alberta

Hospital, 3C1.12 Walter C. Mackenzie Centre, 8440-122 Street,

Edmonton, AB T6G2B7, Canada

e-mail: bagshaw@ualberta.ca 